\title{
Critical Fracture Behavior of a Cu/Al Composite Laminate via the Observation of Scanning Electron Microscope
}

\author{
Zhichao Ma, Hongwei Zhao* and Changyi Liu \\ College of Mechanical Science and Engineering, Jilin University, Changchun, 130025, China
}

In situ fracture study of a $\mathrm{Cu} / \mathrm{Al}$ composite laminate was discussed via the observation of scanning electron microscope (SEM). The experimental test was carried out by a modified miniature tensile device. With the aid of the SEM's sample stage and a wedge block, the profile morphology of the specimen was observed. The substrate layer (1060 aluminum) and the plate layer (C11000 copper) of the specimen presented asynchronous fracture behaviors. Under a relative large strain, a mass of micro voids, cracks and connections of voids and cracks were observed in the substrate layer, accompanied with some separated copper oxide and aluminum oxide flakes. Micro cracks were also observed in the plate layer and the overall morphology of the plate layer was relatively smooth and flat. When the tensile strain increased to 0.26 , the initial fracture position firstly occurred at the plate layer, and the fracture process gradually spread from the plate layer to the substrate layer. In addition, the fracture modes of the substrate layer and the plate layer mainly manifested as microvoid coalescence fracture and pure shear fracture, respectively. [doi:10.2320/matertrans.M2014466]

(Received December 24, 2014; Accepted March 6, 2015; Published May 25, 2015)

Keywords: tensile, composite laminate, fracture, in situ, scanning electron microscope

\section{Introduction}

Metallic multi-layer composites could present fine mechanical performances by using composite technologies and metallurgical technologies on the interfaces of different metals. ${ }^{1-4)}$ Especially, the application of copper/aluminum composite laminates has gradually increased due to the requirements of weight reduction and cost reduction. On account of the advantages of good formability, thermal conductivity, high specific conductivity and good resistance to corrosion, $\mathrm{Cu} / \mathrm{Al}$ composite laminates have been widely adopted in automobile, aerospace and electronics industries. ${ }^{5-9)}$ Besides, in situ tensile testing is a well established characterization method that allows not only the evaluation of the mechanical properties but also the in situ examination of the microstructure and fracture development of the materials. ${ }^{10-17)}$ During the last two decades, by using in situ tensile tests, the mechanical properties and fracture mechanism of $\mathrm{Cu} / \mathrm{Al}$ composite laminates have been deeply investigated. These studies mainly focused on the interfacial strength evolution, the qualitative relationship between the microstructures and the mechanical properties, and the effects of various processing methods on the mechanical properties. ${ }^{2-9,18)}$ For instance, Heness et al. $^{3)}$ studied the interfacial strength evolution of the roll-bonded bi-layered $\mathrm{Cu} / \mathrm{Al}$ laminates and stated that the phases formed in the interfacial zone controlled the interfacial strength, Y. J. Gao et al. ${ }^{4)}$ investigated the microstructure and tensile behavior of $\mathrm{Cu}-\mathrm{Al}$ multi-layered composites prepared by plasma activated sintering, X. B. Li et al. ${ }^{8)}$ also adopted various experimental methods, including micro-hardness, tensile and peeling tests, to investigate the interfacial microstructures and mechanical properties of $\mathrm{Cu} / \mathrm{Al}$ clad sheet. Meanwhile, the micro fracture mechanisms of the substrate material and plate material have also been investigated on basis of the critical fracture behaviors, ${ }^{18-22)}$ such as M. Vratnica et al. ${ }^{18)}$ investigated the effects of alloy purity on the fracture behavior of

*Corresponding author, E-mail: hwzhao@jlu.edu.cn
$\mathrm{Al}-\mathrm{Zn}-\mathrm{Mg}-\mathrm{Cu}$ alloy via the observation of scanning electron microscopy, and D. Dumount et al. ${ }^{19,22)}$ proposed a quantitative relationship between microstructure, strength and toughness of 7050 aluminum alloy, he also proposed a modularized model to predict the fracture mode.

However, the fracture behaviors of the plate layer, substrate layer and interlamination would all have an influence on the fracture mechanism of $\mathrm{Cu} / \mathrm{Al}$ composite laminates respectively, and in consideration of the asynchronous deformation processes of the substrate material and plate material, the critical fracture behavior of the $\mathrm{Cu} / \mathrm{Al}$ composite laminates need to be further discussed, and up to now, the related researches were seldom mentioned. In this paper, in situ fracture study of a $\mathrm{Cu} / \mathrm{Al}$ composite laminate was investigated via SEM observation, and the fracture morphologies of both the substrates layer and plate layer were also studied to better understand the critical fracture behavior.

\section{Experimental Methods}

To conveniently study the interfacial fracture behaviors of the $\mathrm{Cu} / \mathrm{Al}$ composite laminate, the observation of the profile morphology was required. For the horizontal layout in situ tensile devices, the tested specimens were horizontally mounted accordingly, even though with the aid of the SEM's sample stage with five degree of freedoms, the maximum relative angle between the axis of electron gun and the specimen's profile was insufficient to observe the specimen's profile. In this paper, a wedge block with a constant tilted angle of $15^{\circ}$ was fabricated and mounted between the base of the tensile device and the SEM's stage, and the total maximum relative angle could achieve $45^{\circ}$. The material of the wedge block was 2026 aluminum alloy in order to reduce the weight of the tilted stage. The position relationships between the tensile device, wedge block and tilted stage were realized via a group of fastening bolts. Figure 1(a) illustrates the position relationships of these components and the layout of the specimen. As the SEM's tilted stage could provide 

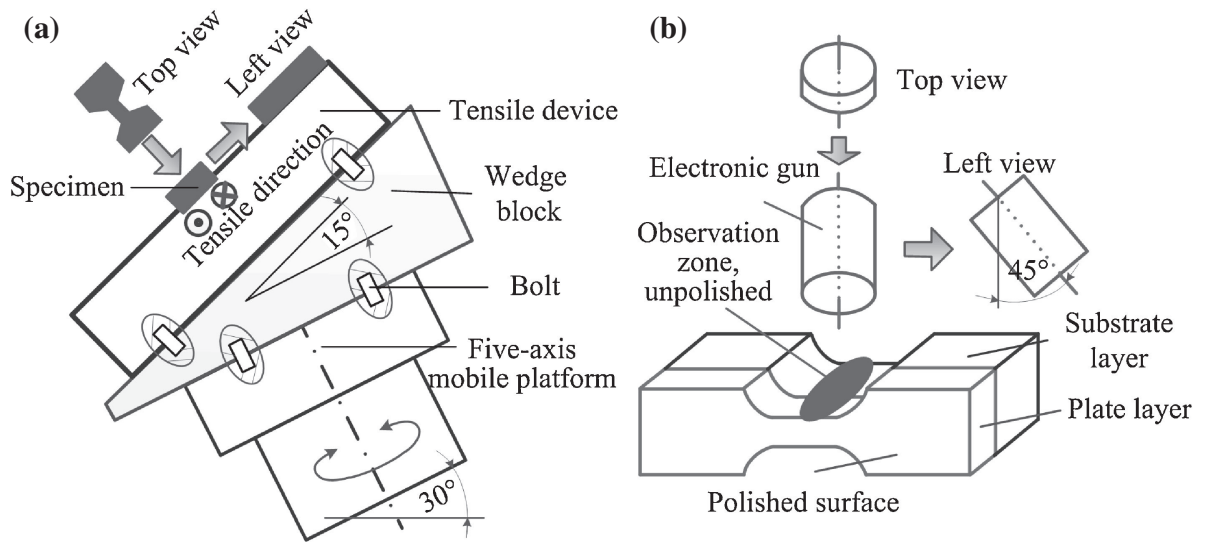

Fig. 1 (a) The tilting layout of the tensile device inside SEM to conveniently observe the specimen's profile morphology. (b) Schematic diagram of observation zone of specimen.

a function of 360 degree rotation, the bilateral profile morphology of the specimen could be observed. Figure 1(b) also shows the position relationship between the SEM's electron gun and the tested specimen. Generally, the $\mathrm{Cu} / \mathrm{Al}$ composite laminate specimen was fabricated by low speed wire cutting, smooth surfaces could be obtained by polishing process on the specimen's upper and nether surfaces, while, the specimen's profile was not easy to be polished due to the circular shape of the transition section. The observation zone, namely the unpolished profile, was actually the wire cutting surfaces consisted of the substrate layer, plate layer and the interlamination.

The in situ tensile test was carried out by a modified miniature tensile device integrating with SEM. The composition, function, gripping method and advantages compared with the existing in situ tensile devices have been reported in detail in the previous work. ${ }^{23)}$ The miniature dimensions allows the device to be compatible with various types of SEM with vacuum chamber large enough, and the larger reduction ratio of the device could realize larger volumeoutput load ratio compared with most existing in situ tensile instruments. Figure 2 shows the structure compatibility with the Zeiss-EVO18 SEM. The long enough working distance of Zeiss-EVO18 SEM could ensure that no contact between the electron gun of SEM and the tensile device occurred during the observation. The specific size of the specimen is also shown in Fig. 2, and the thicknesses of the substrate layer and plate layer were $0.8 \mathrm{~mm}$ and $0.2 \mathrm{~mm}$ respectively.

The adopted $\mathrm{Cu} / \mathrm{Al}$ composite laminate is a typical metal matrix composite, the material of the substrate layer is 1060 aluminum, which presents favorable plasticity and processing properties, and the material of the plate layer is C11000 copper. The composite process of the $\mathrm{Cu} / \mathrm{Al}$ composite laminate mainly consisted of rolling the two different metals together followed by a sintering heat treatment to enhance the bond strength by complex interface phase development. The heat treatment method was diffusion annealing process, the laminate was heated to $300^{\circ} \mathrm{C}$ then kept thermal insulation for 30 minutes to weaken the effects of intermetallic compound on the interfacial properties. As above mentioned, the $\mathrm{Cu} / \mathrm{Al}$ specimen was fabricated by wire cutting, and the initial defects of the unpolished profile would induce the

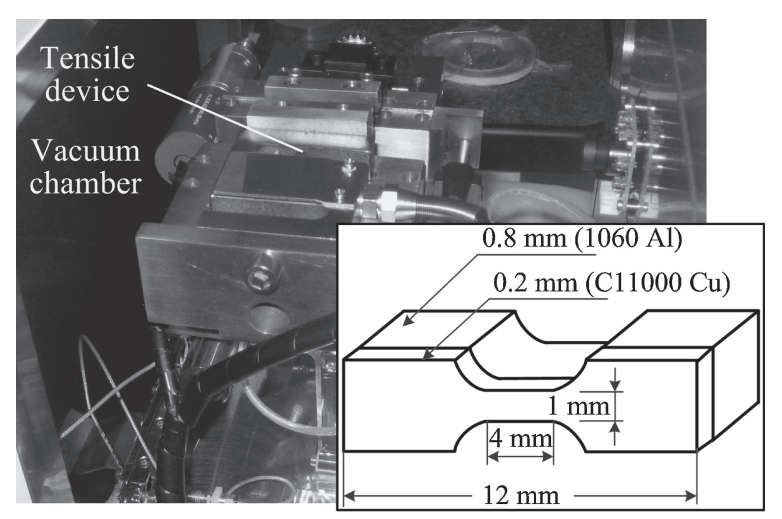

Fig. 2 Prototype of the proposed device including a mounted $\mathrm{Cu} / \mathrm{Al}$ composite laminate specimen.

initial cracks. Figure 3 shows the energy spectrum analysis results of the $\mathrm{Cu} / \mathrm{Al}$ specimen, the adopted energy disperse spectroscopy (Inca X-Max, Oxford Instruments) was integrated with Zeiss-EVO18 SEM. On the plate layer, for the zone close to the interlamination (Point $\mathrm{A}$ as shown in Fig. 3), the chemical composition of copper and aluminum were $69.02 \%$ and $20.58 \%$ respectively, and the chemical composition of oxygen was $10.4 \%$, which indicated that the plate layer was oxidized. Similarly, on the substrate layer, for the zone close to the interlamination (Point B as shown in Fig. 3), the chemical composition of copper and aluminum were $9.76 \%$ and $57.42 \%$ respectively, and the chemical composition of oxygen reached up to $32.92 \%$, which also indicated that the surface layer was oxidized. Furthermore, the thicknesses of oxidation layers were generally within the range from 5 to $15 \mu \mathrm{m}$, in consideration of the overall size of the specimen was millimeter-scale, the effects of oxides on the tensile properties of $\mathrm{Cu} / \mathrm{Al}$ specimen was not significant. Moreover, before being subjected to the tensile load, seen from the specimen's profile morphology shown in Fig. 3, the microstructure of the profile was rough, and the typical diameter of the concave morphology could achieve $20 \mu \mathrm{m}$. Also, almost no obvious copper oxide and aluminum oxide flakes separating from the specimen's profile were observed.

The metallographic structures of the polished plate layer and substrate layer were observed. The adoptive metallo- 

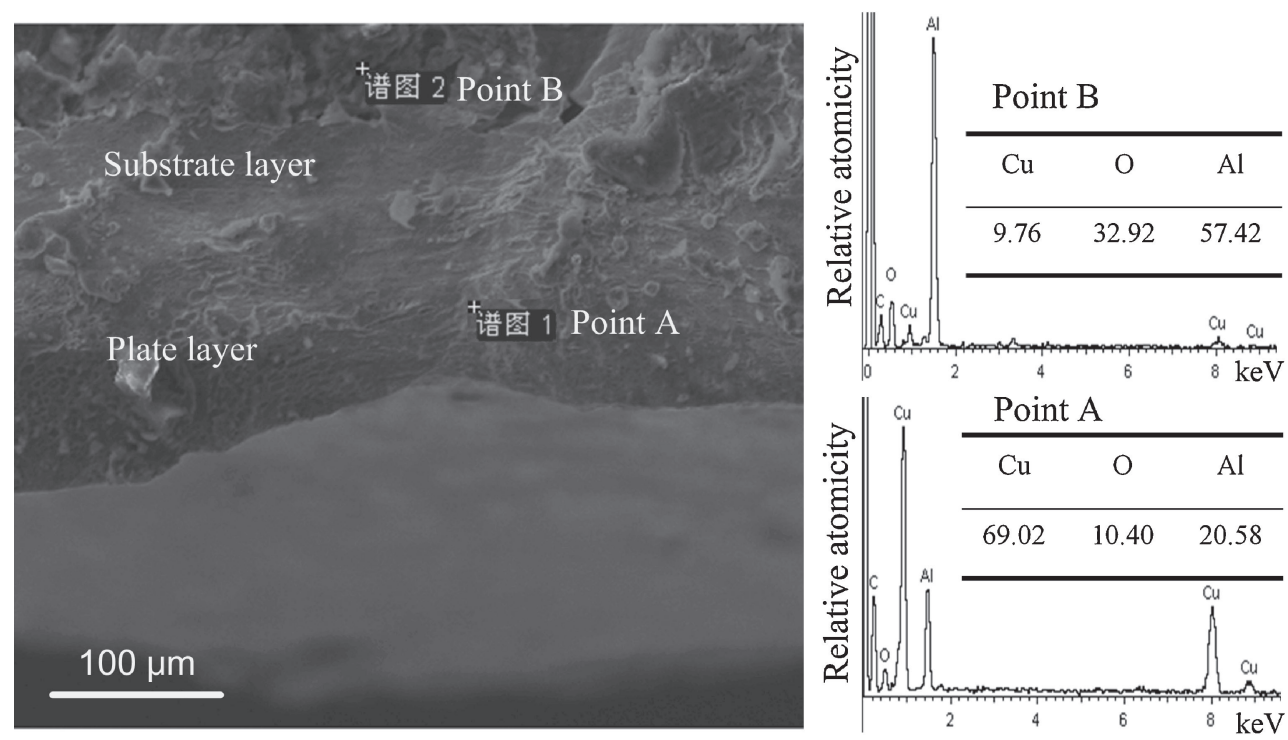

Fig. 3 Alloy composition of the $\mathrm{Cu} / \mathrm{Al}$ composite laminate specimen determined by energy dispersive spectrometer.

graphic microscope (DM2700M, Leica Microsystem) could provide a maximum magnification of over 1000. To obtain the flat surface and metallographic structure, the plate layer was firstly mechanically polished with grinding pastes and abrasive papers with various roughness, then the layer was chemically etched by a ferric trichloride hydrochloric acid aqueous solution. The aqueous solution was consisted of 8 gram trichloride hydrochloric, $50 \mathrm{~mL}$ muriatic acid and $100 \mathrm{~mL}$ distilled water, and the etching time was $10 \mathrm{~s}$. Seen the metallographic microscope boundary map of the plate layer as shown in Fig. 4(a), the average grain size of the plate layer was $8.8 \mu \mathrm{m}$, which was determined on basis of the linear interception method by the commercial metallographic analysis software. Similarly, the flat surface and metallographic structure of the substrate layer was also obtained via mechanical polishing and chemical etching. The acid solution was consisted of $2 \mathrm{~mL}$ hydrofluoric acid, $3 \mathrm{~mL}$ muriatic acid, $5 \mathrm{~mL}$ nitric acid and $190 \mathrm{~mL}$ distilled water, the etching time was $20 \mathrm{~s}$. Seen the boundary map as shown in Fig. 4(c), smaller grain size of $7.1 \mu \mathrm{m}$ was obtained. In addition, the metallographic microscope images of the polished surfaces of the plate layer and substrate layer are shown in Fig. 4(b) and Fig. 4(d) respectively. Compared with the substrate layer, more obvious initial defects, such as micro voids and concave, were observed on the surface of the plate layer, and the diameter of relatively large concave morphology could achieve $2 \mu \mathrm{m}$, which was also measured by the Leica Microsystem analysis software.

\section{Results and Discussions}

Because the tensile strength and elongation after fracture of the 1060 aluminum and C11000 copper were different, the substrate layer and plate layer would present asynchronous fracture behaviors. The tensile mechanical properties of the $\mathrm{Cu} / \mathrm{Al}$ specimen were evaluated by the tensile test inside the SEM (Zeiss-EVO18) with an initial strain rate of $5 \times 10^{-4} \mathrm{~s}^{-1}$. The engineering stress-strain curve of the specimen is shown in Fig. 5, the yield strength and tensile

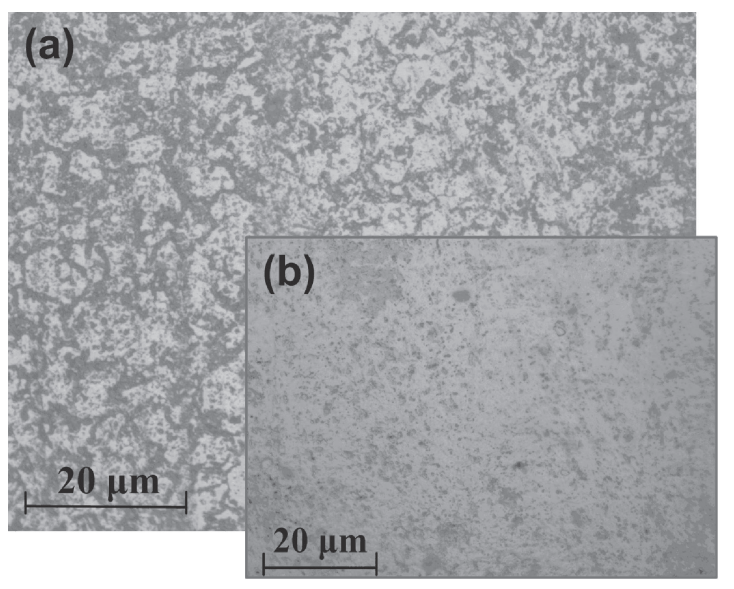

Plate layer

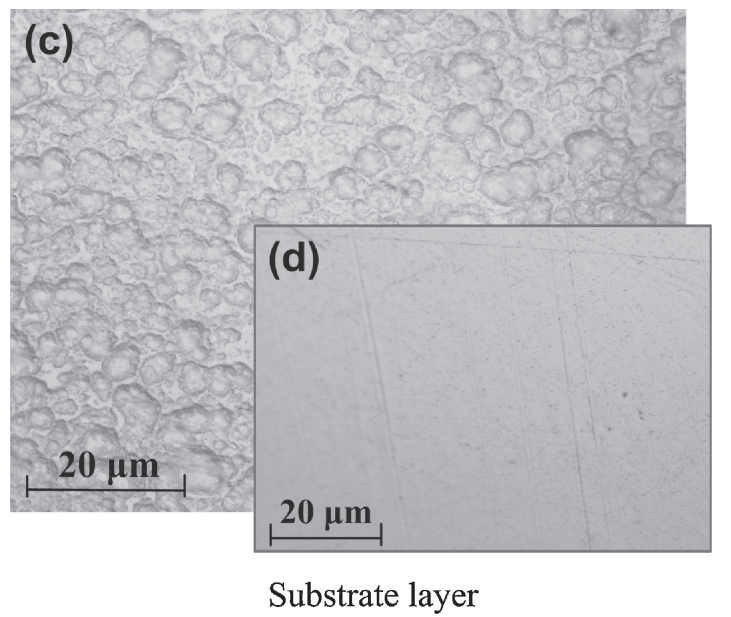

Fig. 4 Metallographic microscope boundary maps of the (a) plate layer and (b) substrate layer combined with the polished surfaces.

strength of were calculated as $171 \mathrm{MPa}$ and $262 \mathrm{MPa}$ respectively. To better understand the critical fracture behavior during the specimen's necking stage, the tensile strains to capture the SEM images were 0.23 and 0.26 respectively, and 
the corresponding stresses were measured as $261 \mathrm{MPa}$ and $257 \mathrm{MPa}$. Figure 6 shows the profile morphology of the $\mathrm{Cu} /$ $\mathrm{Al}$ composite laminate specimen when the tensile strain was 0.23 . The upper and nether layers shown in the figure were the plate layer and substrate layer respectively, the loading direction is also shown in Fig. 6. The necking phenomenon of the specimen was very obvious, a mass of micro voids, micro cracks and the connections of micro voids and cracks were observed in the substrate layer, and the largest diameter of the void even achieved $80 \mu \mathrm{m}$. Some flakes also separated from the substrate layer, via the energy spectrum analysis, the elementary compositions of the separated flakes were oxygen and aluminum, therefore, the flakes could be considered as aluminum oxide. On the other hand, distinct cracks were also observed in the plate layer, but the quantity was relative less, and the global morphology was relative smooth and flat accompanying with a smaller number of copper oxide flakes separated, and the boundary between the plate layer and substrate layer was not very distinct. Additionally, compared with the unpolished profile, the smooth upper surface and nether surface presented more smooth morphologies due to the previous polishing process, the quantity and size of micro voids and micro cracks significantly reduced. The phenomenon indicated that compared with the smooth surfaces, the initial defects (micro voids and micro stress concentrations, for instance) on the specimen's profile caused by wire cutting

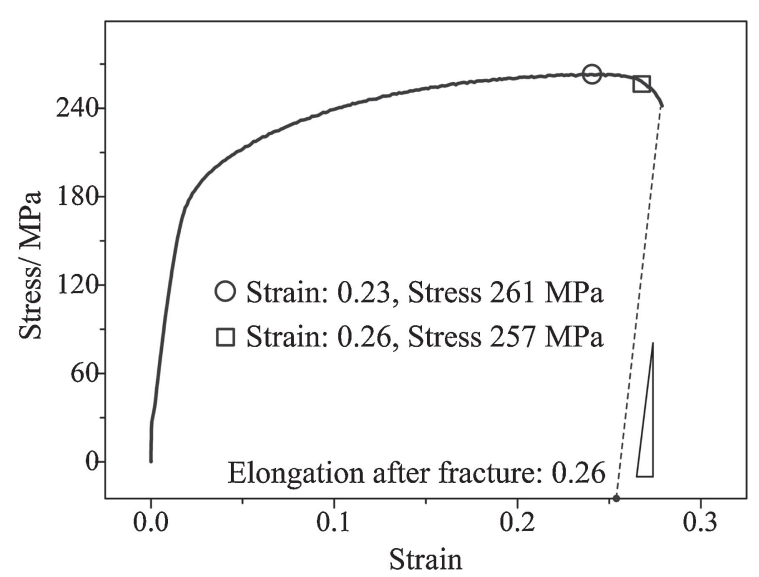

Fig. 5 Engineering stress-strain curve of the $\mathrm{Cu} / \mathrm{Al}$ composite laminate. process would more easily lead to the generation and propagation of the micro voids and cracks. Moreover, generally, the yield strength and tensile strength increase as the average grain size decreases. As above mentioned, the average grain sizes of the plate layer and substrate layer were $8.8 \mu \mathrm{m}$ and $7.1 \mu \mathrm{m}$ respectively, therefore, the ability to undergo tensile stress of the plate layer was weaker compared with the substrate layer. Also, more obvious initial defects were observed on the surface of the plate layer.

Furthermore, the initial fracture of the $\mathrm{Cu} / \mathrm{Al}$ composite laminate specimen occurred when the strain increased to 0.26 , and the profile morphology of the critical fractured specimen is shown in Fig. 7(a). The observation direction was a plane view according to the observation way shown in Fig. 1(a), and the loading direction was the horizontal direction as shown in Fig. 6. It could be clearly observed that the initial fracture position firstly occurred at the plate layer, although distinct main crack was observed in the substrate layer and the substrate layer was in a state of critical fracture, the zones far from the interlamination were still connected tightly. This indicated that fracture of the $\mathrm{Cu} / \mathrm{Al}$ composite laminate gradually spread from the plate layer to the substrate layer, and the fracture in the plate layer occurred anterior to the substrate layer. The elongation after fracture of the plate layer and substrate layer were obtained from uniaxial tensile tests respectively to explain the fracture process of the $\mathrm{Cu} / \mathrm{Al}$ composite laminate specimen. By using wire cut electrical discharge machining, the plate layer and substrate layer were processed into specimens with same specifications and thickness of $0.18 \mathrm{~mm}$, the obtained elongation after fracture of the plate layer was $0.21 \pm 0.024$, which was by far lower than the elongation of substrate layer $(0.029 \pm 0.031)$. Therefore, the fracture firstly occurred at the plate layer with relatively smaller elongation. Figure 7(b) shows the local magnified microstructures of the substrate layer around the main crack, obvious slip trajectories were observed in the zones, and the primary fracture morphology of the zones was tearing dimples. Additionally, plentiful equiaxed dimples and shearing dimples were also observed around the main crack. Therefore, the ductile fracture type of the substrate layer mainly manifested as microvoid accumulation fracture. While, Fig. 7(c) shows the local magnified microstructures of the cracked plate layer, the fracture region was relatively

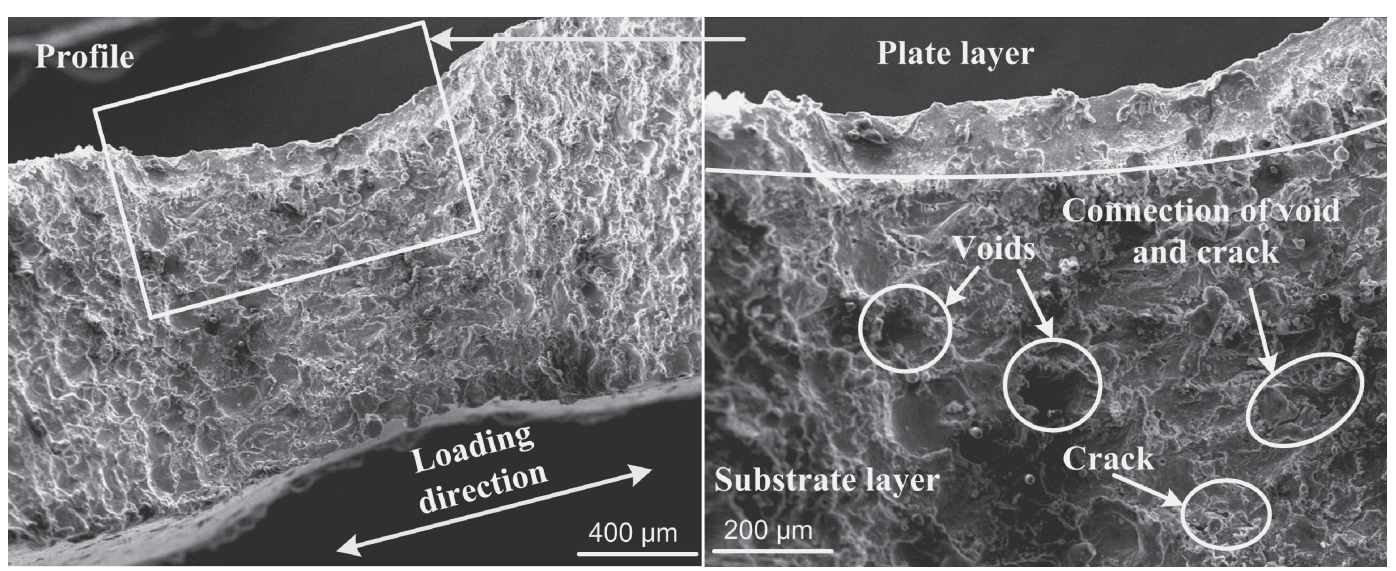

Fig. 6 Profile morphology of the $\mathrm{Cu} / \mathrm{Al}$ composite laminate specimen with a tensile strain of 0.23 . 

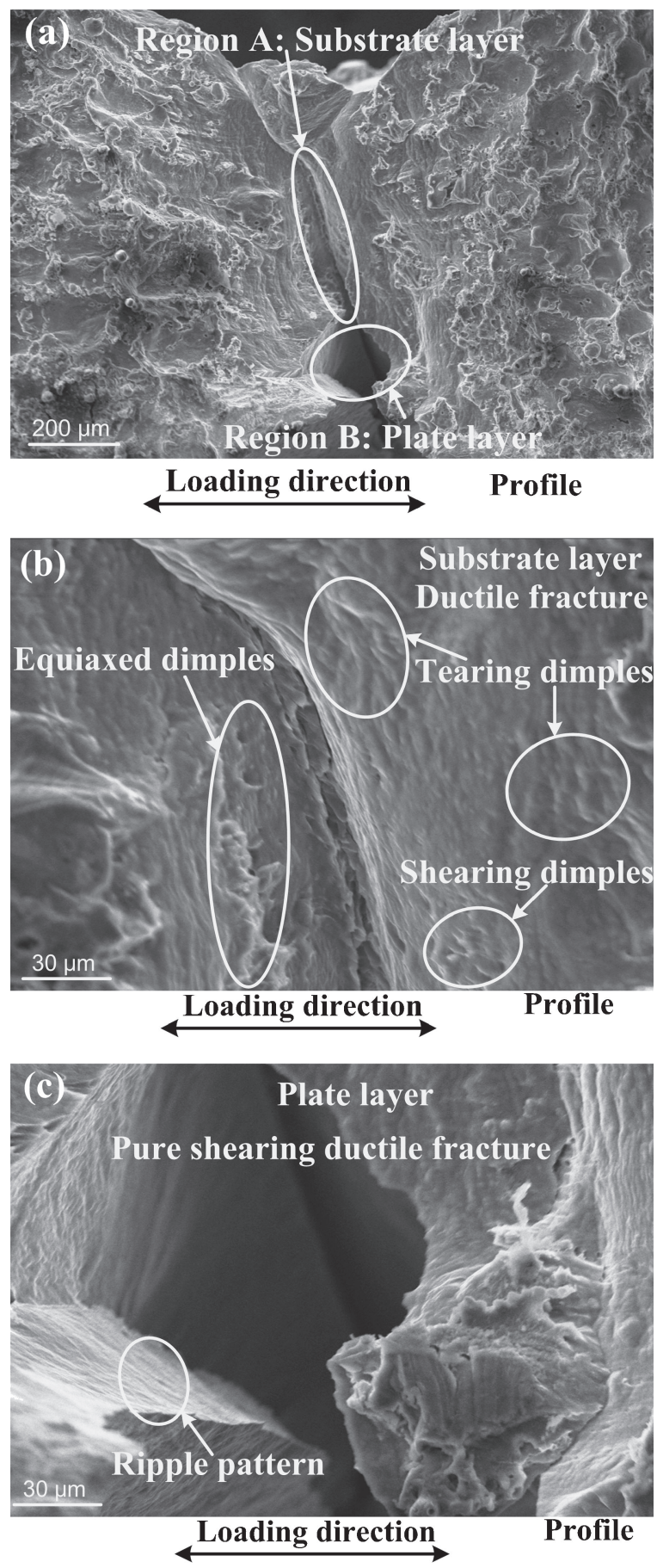

Fig. 7 (a) Critical fracture morphology of the $\mathrm{Cu} / \mathrm{Al}$ composite laminate specimen's profile with a tensile strain of 0.26 . (b) Local magnified microstructures of the substrate layer around the main crack. (c) Local magnified microstructures of the cracked plate layer.

flat and smooth with fibrous ripple pattern. ${ }^{24)}$ The formation process was mainly because the separation of slip planes shaped the crack surfaces, which gradually bent and interlaced during repeated slips, and the serpentine slip pattern gradually formed, as the deformation of plate layer increased, the serpentine slip pattern gradually flattened and the fibrous ripple pattern finally formed. Therefore, the plate layer mainly manifested as pure shearing ductile fracture.

\section{Conclusions}

This paper discussed the critical fracture behavior of $\mathrm{a} \mathrm{Cu} /$ Al composite laminate. Based on the obtained results the following conclusions can be drawn.

(1) The function of a miniature tensile device integrated with SEM was introduced. With the aid of a wedge block, the bilateral profile morphologies of the $\mathrm{Cu} / \mathrm{Al}$ specimen could be observed.

(2) When the tensile strain achieved 0.23 , plenty of micro voids and micro cracks were observed in the substrate layer, accompanying some aluminum oxide flakes separated from the substrate layer, distinct cracks were also observed in the plate layer, but the quantity of cracks was relative less.

(3) The average grain sizes of the plate layer and substrate layer were $8.8 \mu \mathrm{m}$ and $7.1 \mu \mathrm{m}$ respectively, the ability to undergo tensile stress of the plate layer was weaker.

(4) When the strain increased to 0.26 , the initial fracture position firstly occurred at the plate layer, the fracture of the $\mathrm{Cu} / \mathrm{Al}$ composite laminate gradually spread from the plate layer to the substrate layer, the ductile fracture type of substrate layer mainly manifested as microvoid accumulation fracture. For the cracked plate layer, the fracture region was relatively flat and smooth with fibrous ripple pattern and mainly manifested pure shearing ductile fracture.

\section{Acknowledgements}

This research is funded by the National Natural Science Foundation of China (NSFC) (51275198, 51105163 and 51422503), National Hi-tech Research and Development Program of China (2012AA041206), Program for New Century Excellent Talents in University (NCET-12-0238) and Young Scientist Fund of Jilin Province of China (20150520108JH).

\section{REFERENCES}

1) M. C. Chen, H. C. Hsieh and W. Wu: J. Alloy. Compd. 416 (2006) 169-172.

2) X. B. Li, G. Y. Zu, M. M. Ding, Y. L. Mu and P. Wang: Mater. Sci. Eng. A 529 (2011) 485-491.

3) G. Heness, R. Wuhrer and W. Y. Yeung: Mater. Sci. Eng. A 483-484 (2008) 740-742.

4) Y. J. Guo, G. J. Qiao, W. Z. Jian and X. H. Zhi: Mater. Sci. Eng. A 527 (2010) 5234-5240.

5) A. Qiu, K. K. Fu, W. Lin, C. B. Zhao and Y. H. Tang: Mater. Des. 60 (2014) 520-531.

6) G. Sharifishourabi, R. Alebrahim, S. Sharifi, A. Ayob, Z. Vrcelj and M. Y. Yahya: Mater. Des. 59 (2014) 486-493.

7) Y. H. Fu, J. G. Cui and J. W. He: Mater. Sci. Eng. A 355 (2003) 1-6.

8) X. B. Li, G. Y. Zu and P. Wang: Mater. Sci. Eng. A 575 (2013) 61-64.

9) M. Eizadjou, A. K. Talachi, H. D. Manesh, H. S. Shahabi and K. Janghorban: Compos. Sci. Technol. 68 (2008) 2003-2009.

10) J. B. Lin, Q. Wang, W. J. Ren, D. Q. Wang and L. F. Ma: Mater. Trans. 55 (2014) 1180-1183.

11) S. H. Choi, S. Y. Sung, H. J. Choi, Y. H. Sohn, B. S. Han and K. A. Lee: Mater. Trans. 52 (2011) 1661-1666.

12) K. K. Song, S. Pauly, B. A. Sun, J. Tan, M. Stoica, U. Kühn and J. Eckert: AIP. Adv. 3 (2013) 012116.

13) D. Zuo, S. S. Hu, J. Q. Shen and Z. Q. Xue: Mater. Des. 58 (2014) 357362. 
14) Z. C. Ma, H. W. Zhao, Q. C. Li, K. T. Wang, X. Q. Zhou, X. L. Hu, H. B. Cheng and S. Lu: Rev. Sci. Instrum. 84 (2013) 045104.

15) Z. C. Ma, H. W. Zhao, K. T. Wang, X. Q. Zhou, X. L. Hu, S. Lu and H. B. Cheng: Meas. Sci. Technol. 24 (2013) 085901.

16) T. S. Kim and Y. H. Cho: Mater. Des. 58 (2014) 74-88.

17) R. Rizzieri, F. S. Baker and A. M. Donald: Rev. Sci. Instrum. 74 (2003) 4423-4428.

18) Z. Cvijović, M. Vratnica, M. Rakin and I. Cvijović-Alagić: Hilos. Mag. 88 (2008) 3153-3179.

19) D. Dumont, A. Deschamps and Y. Brechet: Acta Mater. 52 (2004) 2529-2540.
20) D. Kiener, C. Motz, M. Rester and G. Dehm: Mater. Sci. Eng. A 459 (2007) 262-272.

21) B. Yang, C. Motz, W. Grosinger, W. Kammrath and G. Dehm: Int. J. Mater. Res. 99 (2008) 716-724.

22) D. Dumont, A. Deschamps and Y. Brechet: Mater. Sci. Eng. A 356 (2003) 326-336.

$23)$ Z. C. Ma, H. W. Zhao, H. Huang, L. Zhang, K. T. Wang and X. Q. Zhou: Exp. Techniques. doi: 10.1111/j.1747-1567.2012.00868.x. (2012).

24) Z. Yajima, Y. Kishi, K. Shimizu, H. Mochizuki and T. Yoshida: Mater. Trans. 47 (2006) 82-89. 